\title{
Para una moral del lenguaje en el regionalismo problemático: Alhué de José Santos González Vera y Vidas Sêcas de Graciliano Ramos
}

\author{
Hugo Herrera Pardo*
}

\begin{abstract}
Resumo
Este artículo expone que las posiciones sobre el lenguaje que adoptan los narradores y personajes de las novelas Alhué de José Santos González Vera y Vidas sêcas de Graciliano Ramos, a partir de la comunión con un espacio agreste, se constituye como una opción crítica frente a los problemas derivados por las nuevas posibilidades de la condición humana impuestas por la Modernidad y sus circuitos de producción. La reflexión en torno a esta "moral del lenguaje" se enmarca dentro de lo que Antonio Candido denomina Regionalismo problemático, tratando de acercar, desde un estudio comparado, algunos puntos de contacto entre representantes del criollismo chileno y la novela del sertón brasileña.
\end{abstract}

\section{Palavras-chave}

Regionalismo problemático. Moral del lenguaje. Alhué. Vidas secas.

\section{El regionalismo problemático y las imposibilidades del lenguaje}

Por su representación de espacios marginales a los circuitos propuestos por la Modernidad, sus estructuras narrativas fragmentarias y desmontables y el lenguaje lacónico que construye ambas novelas, Alhué (1928) de José Santos González Vera y Vidas sêcas (1938) de Graciliano Ramos podrían, entre otras razones, llegar a sostener una comparación. ${ }^{1}$ Es precisamente este el propósito del presente artículo, en específico la perspectiva de cómo esos espacios representados -la aldea, el sertónconfiguran la presentación, como posibles estrategias de resistencia, de nuevas

\footnotetext{
* Doctor, Pontificia Universidad Católica de Valparaíso. Profesor agregado Becario Conicyt. E-mail: hugo.herrera.pardo@gmail.com.

${ }^{1}$ Para el análisis se seguirán Ramos (1986) e González Vera (1976). En las sucesivas citas solo se indicará entre paréntesis el número de página.
} 
posibilidades de entender y significar el lenguaje dentro del panorama y el desarrollo histórico de la narrativa regionalista latinoamericana ${ }^{2}$. El motivo de esta decisión nace a partir del siguiente comentario de Antonio Candido sobre Graciliano Ramos cuando examina el papel de la literatura que él llama regionalista' en la percepción de nuestro continente como un lugar subdesarrollado en términos económicos:

\begin{abstract}
En la fase de preconciencia del subdesarrollo, por los alrededores de 1930 y 1940 , tuvimos el regionalismo problemático, que se llamó "novela social", "indigenismo", "novela del nordeste", según los países, y que, sin ser exclusivamente regional, lo es en buena parte. Este regionalismo nos interesa más, por haber sido un precursor de la conciencia de subdesarrollo [...] A pesar de que muchos de esos escritores se caracterizan por un lenguaje espontáneo o irregular, el paso de la conciencia social actúa a veces en el estilo como factor positivo, y da lugar a la búsqueda de interesantes soluciones adaptadas a la representación de la desigualdad y la injusticia [...] En Vidas Sêcas, Graciliano Ramos lleva al máximo su habitual contención verbal, elaborando una expresión reducida a la elipsis, al monosílabo y a los sintagmas mínimos, para expresar la opresión humana del vaquero, confinado a los niveles mínimos de supervivencia. (CANDIDO, 1991, p. 316-7)
\end{abstract}

Candido ve en el regionalismo problemático una estilización muy especial del lenguaje. Este rasgo especial se signa en una reducción a un nivel mínimo, casi al nivel del animal, del lenguaje verbal articulado; reducción a un balbuceo lingüístico que viene a simbolizar la privación a la que se ven sometidos los personajes de estas ficciones en términos de relaciones espaciales ${ }^{3}$, de allí uno de los logros de esta literatura en cuanto objeto artístico. En el caso particular de Vidas sêcas, Cándido ve en ella un expresión verbal reducida a la elipsis, al monosílabo y a los sintagmas mínimos, con el objetivo de manifestar la opresión humana a la que se ve sometido el vaquero, confinado a los niveles mínimos de supervivencia, factores que aquí atribuimos a una práctica espacial productiva; una organización y distribución de espacio habitado en base a criterios económicos, hecho que termina mermando otras instancias sociales, entre ellas, la cultura.

En la familia de retirantes que protagoniza la novela de Graciliano Ramos, este "balbuceo lingüístico" se concretiza en distintas expresiones, cada una con matices y ribetes diferentes: "Sinha Vitoria estirou o beico indicando vagamente uma direcao e afirmou com alguns sons guturais que estavam perto". (p. 10).

Los sonidos guturales de Sinha Vitoria, resultan simbólicos en la medida en que se encuentran al comienzo del libro, siendo ese sonido gutural el que anuncia al resto de la familia un lugar más o menos propicio donde establecerse, después de haber caminado horas bajo el sol, con el suelo lleno de espinas y guijarros, junto a un barro seco y resquebrajado que ya escaldaba los pies. Es el momento en que las llagas de

2 El término está tomado de Antonio Candido quien, siguiendo la tradición de la crítica latinoamericana, se refiere a toda la ficción que abarca la descripción de regiones y costumbres rurales desde el Romanticismo. Aunque reconoce que los primeros movimientos Regionalistas desarrollaban más que nada un pintoresquismo meramente decorativo, asume que entre la década del treinta y del cincuenta del siglo pasado la literatura regionalista existió como conciencia crítica, superando el optimismo patriótico romántico y el pesimismo de la ficción naturalista.

3 Cándido cita como ejemplos de estas ficciones a Miguel Ángel Asturias y Jorge Icaza, por nombrar algunos. El comentario que desvía a esta nota se encuentra referido a éste último, en específico a su novela Huasipungo. 
los mismos ya comienzan a sentirse con más agudeza, en especial en Fabiano, quien carga con el zurrón en bandolera, el cuenco colgando de una correa sujeta al cinturón y la espingarda de pedernal al hombro. Es el inicio de la novela, y un hecho positivo, uno de los pocos en todo el texto, solo es anunciado con un sonido gutural e indicando la dirección con el labio estirado. En cambio, lo simbólico en Fabiano toma ribetes más políticos:

Fabiano tambem nao sabia falar. As vezes largava nomes arrevesados, por embromacao. Via perfeitamente que tudo era besteira. Nao podia arrumar o que tinha no interior. Se pudesse... Ah! Se pudesse, atacaria os soldados amarelos que espancam as criaturas inofensivas. (p. 36)

Así, estas palabras enrevesadas de Fabiano resultan simbólicas en tanto dan una explicación del balbuceo lingüístico en relación con el centro organizativo detrás de la distribución productiva del espacio. Es el capítulo Cadeia, en donde Fabiano cae preso en su primer viaje a la ciudad -centro del poder, por culpa del soldado amarillo, que lo provoca hasta llevarlo a pasar una noche en la cárcel. El vaquero en su imposibilidad de saber hablar, lanza palabras enrevesadas, por broma, esta incapacidad no le permite defenderse frente al soldado amarillo, metonimia del gobierno, o en otras palabras, metonimia del poder.

Estos balbuceos ante el lenguaje trascienden hacia los más pequeños. El hijo menor, para llamar a su hermano y a la perra, bala, el hijo mayor como no sabía hablar bien, balbuceaba, repetía sílabas, igualmente imitaba a los animales. "Pos-se a berrar, imitando as cabras, chamando o irmao e a cachorra. Nao obtendo resultado, indignou-se." (p. 51).

Esto le hacía sentir que debía aprender una palabra para imitar a su hermano:

Como nao sabia falar direito, o menino balbuciava expressoes complicadas, repetia as silabas, imitava os berros dos animais, o barulho do vente, o som dos galhos que rangiam na catinga, rocando-se. Agora tinha tido a ideia de aprender uma palavra, com certeza importante porque figurava na conversa de Sinha Terta. Ia decora-la e transmiti-la ao irmao e a cachorra. Baleia permaneceria indiferente, mas o irmao se admiraria, invejoso. (p. 59-60).

En consecuencia, esta actuación para con el lenguaje marcará igualmente sus relaciones. Los diálogos entre los padres son solo repeticiones, sonidos guturales e incongruencias, difícilmente aprenderán sus hijos una palabra de ellos. En esos diálogos ninguno prestaba atención a las palabras del otro, porque no sabían comprenderlas:

Quando iam pegando no sono, arrepiavam-se, tinham precisao de virar-se, chegavam-se a trempe e ouviam a conversa dos pais. Nao era propriamente conversa, eram frases soltas, espacadas, com repeticoes e incongruencias. As vezes uma interjeicao gutural dava energia ao discurso ambiguo. Na verdade nenhum deles prestava atencao as palavras do outro: iam exibindo as imagens que Ihes vinham ao espirito, e as imagens sucediam-se, deformavam-se, nao havia meio de domina-las. Como os recursos de expressao eram minguados, tentavam remediar a deficiencia falando alto. (p. 63-4). 
En sus relaciones repetían más sonidos que palabras, al no poder repetir estas últimas fracasa la historia que Fabiano pretendía contarles a sus hijos. "Teria sido melhor a repeticao das palavras. Altercaria com o irmao procurando interpreta-las. Brigaria por causa das palavras - e a sua conviccao encorparia." (p. 68)

Por culpa de este hecho, por no poder interpretar las palabras, los niños terminarán peleando. El lugar oprime no solo por sus causas geográficas, éstas se agudizan por el poder desde el centro, desde la ciudad, que debido a la improductividad del sertón, lo termina marginando y con ello a sus habitantes, en todas las instancias de realización social, entre ellas el lenguaje.

En Alhué de José Santos González Vera encontramos una dificultad similar en relación con el lenguaje, pero en este caso, estilizada por medio de un contraste entre quien sí logra expresarse por medio del lenguaje verbal articulado y la mayoría del pueblo que vive en el silencio, en la monotonía que produce la marginalidad alienante de la productividad moderna. Uno de estos personajes es el viejo Aliste, EI sepulturero, en cuya lengua "dormían setenta años de paisajes, ruidos, leyendas y meditaciones." (p. 102):

\footnotetext{
-Dígame, Aliste, ¿de dónde saca usted tantas cosas?-preguntaba el cazador.

-Yo mismo no lo sé bien... Me figuro que en la cabeza tengo una bolsa, pues basta que diga una palabra para que las demás vayan cayendo sin remedio, casi contra mi voluntad. Es cierto que cuando uno larga cuanto se le viene a la cabeza, se le para la lengua sin forzamiento.

Y en cada punto aparte, Aliste purificaba su voz vaciando una copa de aguardiente. Donde abría camino propio era en la calificación de los fenómenos. Las ideas y las figuras, la realidad y la fantasía ocupaban el vasto, pero único plano de su cerebro. Hablaba de la trilla y el Infierno como de cosas próximas y convergentes. (p. 107)
}

Más que el poder hilar sin torpeza las palabras, es la capacidad de Aliste de poder asociar los más distintos fenómenos por medio de éstas lo que impresiona al cazador, es decir, más que la sintaxis, le asombra la semántica, mientras que el asombro en Vidas sêcas, en las citas anteriormente vistas, responde más a un carácter fónico, que podría explicarse por la representación agreste de la animalización del hombre en Vidas sêcas, nacida de las características totalmente límites del sertón brasileño. Podríamos señalar en este sentido que la correspondencia entre espacio físico y lenguaje se establece inclusive en una relación indirectamente proporcional: a mayor crudeza geográfica menor nivel en la escala de rango del lenguaje. Otro personaje que logra construir discursos verbales fluidos en Alhué es la esposa de Ismael, discurso producido por la resignación de ella ante la vida que llevan:

\footnotetext{
Las palabras que seguían al porque de su mujer, terribles, candentes y alusivas palabras, no cesaban. Lo perseguían, lo hacían transpirar, le provocaban una especie de borrachera. La sangre se le iba camino de la cabeza. En vano procuraba silbar entre dientes. Nada. Poco a poco entrábale el deseo vehemente de asir a su mujer y pegarle sin lástima, hasta silenciarla; pero no estaba bien alborotar a diario. Además, de no rematarla, el remedio resultaría peor que la enfermedad. Le daría asunto para mover la lengua un mes entero. (p. 120-1)
} 
El contraste al que aludimos queda más explícito en la medida en que Ismael le teme más a las palabras de su mujer que a ella misma, a la que desearía golpear, pero no lo hace para no seguir oyéndola. Intenta combatir el discurso de su mujer con elementos fónicos -el silbido-, como en Vidas sêcas, pero la intención resulta en vano. En este caso eso sí, más que la semántica, lo que aterra a Ismael es la sintaxis.

En todos los casos vistos hasta aquí, lo que se presenta es la imposibilidad de dominar el lenguaje, en correlación a la derrota que propina la tierra que cobija, debido a factores geográficos en Vidas sêcas y a factores temporo-espaciales en Alhué. A esta incapacidad de decir, Barthes (1987) la llama el "farfulleo" de la lengua, incapacidad que guarda estrecha relación con las propias limitaciones del lenguaje. Para Barthes, farfullar es la fatalidad de la palabra de no poder ser irreversible, "Lo que ya se ha dicho no puede recogerse, salvo para aumentarlo: corregir en este caso, quiere decir, cosa rara, añadir." (BARTHES, 1987, p. 99). Se trata, entonces, de una anulación por adición. Fabiano ante la imposibilidad de hablar bien, profiere palabras enrevesadas; el hijo mayor lanza balbuceos y expresiones complicadas ante la misma imposibilidad; la mujer de Ismael no se detiene en recriminar a su esposo, si este llegase a golpearla, tampoco llegaría a hacerlo; Aliste no sabe que todo lo que construye con su discurso no llega a representar de manera directa a la realidad, debido a los límites del lenguaje, sin embargo lo suyo es enunciar y enunciar. Estos ejemplos solo "farfullan" con el lenguaje; en apariencia fracasan doblemente: fracasan ante la imposibilidad de dominar un lenguaje imposible.

\section{Resistencias de lo local: el susurro de la lengua}

Sin embargo, tanto en Alhué como en Vidas sêcas, este fracaso se encuentra en disposición de fortalecer, estilísticamente, la resistencia que otorgan estas novelas, en tanto resistencias de lo local, ante un lenguaje imposible que, paradójicamente, es el esquema material del género que construye. Siguiendo a Barthes (1987), en estas novelas encontramos esa utopía del lenguaje que él llama el "susurro de la lengua", en algunos casos dados por los mismos oyentes de los discursos-farfulleos, como Aliste, El sepulturero, o en otros, inclusive, por los mismos hablantes que, al comienzo del relato, farfullaban, como Fabiano.

El susurro, nos dice Barthes, es el sonido que produce lo que funciona bien, como el de las máquinas, símbolo de la perfección. El susurro, así, se opondría al farfulleo, que es un ruido. En este sentido, el susurro no es más que el ruido de la ausencia de ruido. Un ruido límite. En relación con la lengua:

[...] ese susurro sería ese sentido que permitiría oír una exención de los sentidos, o - pues es lo mismo- ese sin-sentido que dejara oír a lo lejos un sentido, a partir de ese momento liberado de todas las agresiones, cuyo signo, formado a lo largo de la "triste y salvaje historia de los hombres" es la caja de Pandora. (BARTHES, 1987, p. 101). 
Tanto en Alhué como en Vidas sêcas, estos susurros serían los sonidos guturales y monosilábicos de sus personajes. Estos sonidos en las novelas funcionan a la perfección, en tanto acusan que los discursos ajenos, los discursos otros (plurisilábicos, como la señora de Ismael, o como el Fabiano o Sinha Vitoria del inicio del relato que "farfullan") son disfuncionales, meros farfulleos, como los emitidos por Don Nazario, dueño del almacén "El tropezón", en la novela de González Vera:

Su dueño, don Nazario, sudaba angustia, porque aborrecía el silencio y carecía de iniciativa interior. Quizás le hubiera convenido más abrir una cantina en la ciudad; pero tampoco podía sufrir una situación nueva. Todo lo desconocido le horrorizaba. (p. 31)

\footnotetext{
Le gustaba que los demás hablasen. Los charlatanes le inspiraban respeto. La posibilidad de asociar muchas palabras maravillábalo. Tal vez entendía las palabras, pero en sus relaciones con los demás no emitía más de cuatro.

Su frase de ceremonia era ésta:

- iAh! sí, como no.

De ordinario bastábale la mitad.

Nadie pudo superarle nunca en su buen uso. Cuando recibía una proposición de crédito, para indicar que lo resistía un poco, pero que cedía por rara deferencia, profería un pensativo «Aaaa... sí». Y si le contaban algo próximo a lo inverosímil, su comentario era « ¿Ah... sí?». Variaba la expresión si el visitante le interrogaba sobre la marcha del negocio. La fórmula exacta concretábase «Así-así...». Y bastaba. La elocuencia estaba en sus manos de larguísimos dedos. (p. 32-3)
}

Ante la disfuncionalidad de aumentar la fatalidad de la palabra, Don Nazario solo emite significantes, procurando llevar a cabo una "irrealización semántica", Barthes (1987), propia del farfulleo, ya que con esos significantes no extiende la significación, porque lisa y llanamente esta no llega a realizarse del todo, para así no recaer en la misma fatalidad que su interlocutor. Similar posición adopta Ismael, el pescador, ante las preguntas de sus compañeros de oficio:

- ¿Y cómo va el baile?

-Así, así...-respondía haciendo un gesto de enfado.

No se volvía a tocar el asunto. En cambio, el río entraba en la conversación, y la pieza se llenaba de peces legendarios. (p. 121)

Lo que ocurre aquí es una irrealización semántica similar a la producida por Don Nazario, solo que al final la evaporación del ruido que constituye el susurro de la lengua completa su finalidad con la belleza de sonido introducido por el río. En este sentido, también existen expresiones que encierran mayor complejidad: "- iAh! Esa exclamación terminantísima equivalía también a: maldita sea, me recondenara o peor es morirse." (p. 120).

iAh! es un significante que se adjudica un triple movimiento de significancia, lo que es utopía del lenguaje, en cuanto realiza la operación inversa del farfulleo: a) reduce la expresión; b) sin embargo esta termina siendo igualmente aditiva; c) en consecuencia no cae en la anulación. Es interesante rescatar que esta acción es 
respaldada por el narrador con enunciados como: "De ordinario bastábale la mitad" o "No se volvía a tocar el asunto".

El caso de Vidas sêcas, resulta ser en este sentido, más complejo, ya que la oposición, el contraste del tema se desarrolla simultáneamente en los mismos personajes, al contrario de Alhué en donde el tema se confronta entre personajes, así que lo que se nos descubre al comienzo como imposibilidad, como falencia, comienza igualmente a inscribirse como crítica:

\begin{abstract}
Vivia longe dos homens, so se dava bem com animais. Os seus pes duros quebravam espinhos e nao sentiam a quentura da terra. Montado, confundia-se com o cavalo, grudava-se a ele. E falava uma linguagem cantada, monossilabica e gutural, que o companheiro entendia. A pe, nao se aguentava bem. Pendia para um lado, para o outro lado, cambaio, torto e feio. As vezes utilizava nas relacoes com as pessoas a mesma lingua com que se dirigia aos brutos - exclamacoes, onomatopeias. Na verdade falava pouco. Admirava as palabras compridas e dificeis da gente da cidade, tentava reproducir algumas, em vao, mas sabia que elas eram inuteis e talvez perigosas. (p. 19)
\end{abstract}

Fabiano, a pesar de la sensación atrayente que le causa la retórica del lenguaje, toma conciencia de lo inútiles y peligrosas que son las palabras. Justamente por estos últimos atributos dirigidos hacia la palabra es que él prefiere comunicarse por monosílabos y, en este sentido, es que se comunica mejor con los animales. Lo que inicialmente parece ser una incapacidad del vaquero, guarda en su trasfondo una crítica ácida. En este mismo sentido encontramos el siguiente pasaje:

\begin{abstract}
sempre que os homens sabidos the diziam palavras dificeis, ele saia logrado. Sobressaltava-se escutando-as. Evidentemente so serviam para encubrir ladroeiras. Mas eram bonitas. As vezes decorava algumas e empregava-as fora do proposito. Depois esquecia-as. Para que um pobre da laia dele usar conversa de gente rica? Sinha Terta e que tinha uma ponta de lingua terrivel. Era: falava quase tao bem como as pessoas da cidade. Se ele soubesse falar como Sinha Terta, procuraria servico noutra fazenda, haveria de arranjar-se. Nao sabia. Nas horas de aperto dava para gaguejar, embaracava-se como um menino, cocava os cotovelos, aperreado. Por isso esfolavam-no. Safados. Tomar as coisas de um infeliz que nao tinha onde cair morto! Nao viam que isso nao estava certo? Que iam ganhar com semelhante procedimento? Hem? Que iam ganhar? (p. 96-7)
\end{abstract}

Fabiano es estafado por medio de las palabras, lo que no termina constituyendo una denigración, debido a las preguntas finales que lanza, interrogaciones acuciosas que delatan en último término, el fenómeno que termina organizando y distribuyendo el espacio de manera desigual: el dinero, y por el que nacen, en los comienzos de la modernidad, los nuevos circuitos de producción. Esta crítica al lenguaje verbal articulado, se consolida con el delatamiento de la permeable irrealización semántica a la que es susceptible la palabra, cuando emite algunas de ellas fuera de contexto. Por esto su elección de un lenguaje monosilábico y gutural, un susurro del lenguaje, el que a veces incluso utiliza en su relación con las personas. A esto último también se debe la decisión del matrimonio de comunicarse por medio de monosílabos, Sinha Vitoria: "Reanimou-se, tentou libertar-se dos pensamentos tristes e conversar com o marido por monossilabos" (p. 118-9). 
Ante la opacidad de la palabra, que la termina haciendo históricamente un lenguaje cargado de segundas intenciones que refieren a ideologías que buscan ser dominantes, los susurros de la lengua de Don Nazario, Ismael, Fabiano, Sinha Vitoria, por citar a algunos personajes, terminan purificando a la palabra por medio de una dosis de transparencia, en tanto que neutraliza la desviada significación del lenguaje verbal articulado. Es como una especie de, parafraseando al mismo Barthes, "grado cero"; una expresión neutra, que lleva a cabo un movimiento de negación y de imposibilidad de realización, "como si la Literatura [...] encontrara la pureza en la ausencia de todo signo." (BARTHES, 1967, p. 12).

Llegados a este punto resulta pertinente plantearse la pregunta que se hace Barthes con respecto a la utopía del susurro del lenguaje, en cuanto esta utopía, para ser tal, debe guardar relación con la música, debido a que este es el lenguaje perfecto, ya que cumple con los dos requisitos provistos por Lévy-Strauss ${ }^{4}$ para tal condición, a saber, 1) ser únicamente para sí, esto es, intraducible, y 2) ser, a pesar de lo anterior, comprensible inmediatamente. A causa de esto, y al decir de STEINER (2000, p. 68), solo "en la música nuestras vidas ensordecidas pueden obtener de nuevo un sentimiento de movilidad interior y de la coherencia del ser individual, y nuestras sociedades algo de la perdida visión de una concordia humana." En este sentido, los casos anteriormente revisados de significantes monosilábicos y expresiones guturales de los personajes de las novelas analizadas, sí cumplen con los dos requisitos planteados por Lévy-Strauss para ser lenguaje perfecto $y$, del mismo, apreciamos que este susurro-lenguaje perfecto critica la "perdida visión de la concordia humana" (Steiner), lo que constituye, en algún sentido, restituirla.

$Y$ es en esta crítica en donde este susurro del lenguaje encuentra su "horizonte de sentido" (BARTHES, 1987), posición que excluye a esta operación sobre el lenguaje como una crítica sin fundamento, ya que como plantea el mismo Barthes: "La lengua, susurrante, confiada al significante en un inaudito movimiento, desconocido por nuestros discursos racionales, no por ello abandonaría un horizonte de sentido..." (BARTHES, 1987, p. 101). Este horizonte de sentido, sería de manera más precisa, la crítica a la racionalidad homogeneizadora de la modernidad, en tanto es ella, ese discurso racional, al que alude Barthes, que desconoce estos significantes que vienen a ser la resistencia del Otro; la alteridad, frente a la mismidad que propone el proyecto de la modernidad, con su racionalización y abstracción del tiempo y el espacio y sus consiguientes efectos.

\section{3. $\varphi$ : presencias fantasmáticas}

Las reflexiones realizadas hasta el momento nos permiten afirmar que en las novelas se manifiestan, de manera fantasmática, distintas voces que resuenan a lo largo de los textos, e inclusive voces dentro de aquellas mismas voces, y que están allí, paradójicamente, para tensionar la imposibilidad de su función. En otras palabras, al interior de estas novelas encontramos una particular polifonía, de acuerdo al

\footnotetext{
${ }^{4}$ Cf. Steiner (2000. p. 68).
} 
término bajtiniano. No debe parecer extraño que estas poli-fonías se den de manera fantasmática. De hecho fonía y fantasma provienen de una misma raíz $(\varphi)$, que alude a la presencia ante los sentidos, que en los casos de las novelas estudiadas corresponde a una presencia mediante una aparente ausencia, una presencia fantasmática. Esta relación se estrecha aún más si consideramos lo que plantea Silva con respecto a los fantasmas, quienes "desde sus orígenes son seres invisibles que nos hablan, que se dejan ver, que aparecen y se van" (SILVA, 2006, p. 110, la cursiva es nuestra). Los susurros de las palabras, y por ende de sus voces, tanto en Alhué como en Vidas sêcas, funcionan como fantasmas: están allí de manera invisible, transparente como señalamos más arriba, para tensionar el lenguaje humano, junto con los discursos que este construye y, asimismo, lo que ellos simbolizan, esto es, la opresión, que, como se señaló anteriormente, es un paralelismo de las consecuencias de la práctica espacial productiva. Lo importante de esto es la reflexión que surge del vínculo límite del lenguaje- identidad, ya que, como advierte Conejo Polar, es en el lenguaje donde resiste la identidad. A fin de cuentas, esta acción de balbuceos y susurros de la lengua es una moral del lenguaje, en los términos propuestos por Barthes al pensar que "el lenguaje nunca es inocente: las palabras tienen una memoria segunda que se propaga misteriosamente en medio de significaciones nuevas" (BARTHES, 1967, p. 20). Esta moral del lenguaje de los personajes de Alhué y Vidas sêcas lleva al lenguaje a su límite para que, junto con acusar esta presunta inocencia, se logre construir una identidad sin memorias segundas que propaguen misteriosamente nuevas significaciones.

Apuntamos anteriormente que la crítica ante las limitaciones del lenguaje se daba en Alhué de manera oposicional entre personajes, mientras que en Vidas sêcas se daba al interior de las mismas voces. Este hecho deja a la impresión de que se construye al interior de esas mismas voces una especie de palimpsesto, en el sentido señalado por Genette, en referencia a la obra de Proust, en la cuál se confunden y encabalgan varias figuras y sentidos, por medio de sucesivas capas temporales que se sobreponen y se reemplazan. En las novelas analizadas, como se dijo, esta yuxtaposición ocurre en las voces $y$, de la misma manera que este hecho responde a capas temporales, también, tanto en Alhué como en Vidas sêcas, responde a capas espaciales; eso explicaría que este mismo fenómeno se de en el padre del narrador homodiegético testimonial de la novela de González Vera, al igual que en los migrantes de la novela de Ramos. Dice el narrador de Alhué con respecto a los discursos de su padre:

Hablaba con mucha seguridad y su voz iba de un tono a otro como si dentro de sí fueran varios los que hablasen.

A veces, cuando su voz se mantenía unitonal, sus oyentes recibían la sensación de estar percibiendo una voz lejana. (p. 36)

Se trata de un palimpsesto igualmente de atributos fantasmáticos, ya que se sobreponen y reemplazan en algunos momentos del texto (como en la anteriormente citada percepción de Fabiano de que "Admirava as palabras compridas e dificeis da gente da cidade, tentava reproducir algumas, em vao, mas sabia que elas eram inuteis 
e talvez perigosas.") a la voz que funciona como contrapunto dramático de la situación de opresión que sufre la familia. Esta presencia fantasmática de otra voz al interior de una voz migrante queda bien graficada en Alhué (en el padre del narrador), en aquél segundo enunciado que citamos como ejemplo: "A veces, cuando su voz se mantenía unitonal, sus oyentes recibían la sensación de estar percibiendo una voz lejana", el contrapunto radica allí en la voces que pueblan la voz del padre, inclusive cuando esta pronuncia de manera unitonal, lo que nos quiere decir que el hecho de que sean varios los que hablan en aquella voz no guarda relación con el cambio de tono o no, es algo intrínseco, consustancial a su ser, debido a su condición migrante; por esto mismo es una voz lejana, porque está indicando un espacio signado en el allá/entonces, en la memoria del sujeto migrante.

\section{Dialogismo y silencio}

Este palimpsesto fantasmático de voces, caracterizadas mediante una presencia aparentemente en forma de ausencia, funciona como una trampa de lectura si pensamos en el dialogismo presente en las novelas analizadas. Se podría pensar que tanto Alhué como Vidas sêcas constituyen un relato absolutamente monológico, debido a que no existen en ellas narradores delegados. Sin embargo, esta defectividad narrativa, si se quiere llamarlo así, encuentra su primer punto de fuga en el trabajo con el discurso directo de los personajes.

Veamos primero el caso de Alhué. Si bien el narrador homodiegético que oscila entre el tipo testimonial y el autodiegético impone la enunciación narrativa desde un tiempo muy posterior al acontecimiento de la narración, esta voz se rompe en ocasiones al otorgarle esta condición de voz a los personajes, para que ellos mismos refieran sus propios discursos. Sirvan de ejemplos los siguientes fragmentos, el primero de ellos, ya citado, referido a don Nazario:

Su frase de ceremonia era ésta:

- iAh! sí, como no.

De ordinario bastábale la mitad. (p. 32)

Y este referido a Loreto:

Entonces iba a su farmacia de frascos verdosos, volvía con una toma y se la ofrecía siempre en los mismos cariñosos términos:

-Me dice el corazón que le hará bien.

Mi tía murió a los dos años completamente vegetalizada.

En Vidas Sêcas, en tanto, ocurre algo similar. También se podría pensar que es un relato altamente monológico, pero termina por desequilibrar esta idea el mismo procedimiento que en la novela de González Vera. Existe en el relato de Ramos la técnica del discurso directo de los personajes para quebrar la univocidad del relato impuesta por su narrador heterodiegético: 
Olhou em torno, com receio de que, fora os meninos, alguem tivesse percebido a frase imprudente. Corrigiu-a, murmurando:

- Voce e um bicho, Fabiano. (p. 18)

Si bien es cierto que Genette llevó esta característica de metalepsis en los diálogos hasta una exageración, es en este tipo de relatos, como Alhué y Vidas Sêcas, en los que existiendo un narrador que domina casi a cabalidad todo el relato, la metalepsis presente en los diálogos es de mayor potencia, debido al contrapunto que se establece entre el narrador que aparentemente lo domina todo y la voz del personaje que irrumpe en determinadas ocasiones para referir con su propia voz su discurso. Así, en suma, en estas novelas no se aprecia un alto grado de principio de incertidumbre en términos de discursividad narrativa, sino que esta problemática se traslada a la discursividad propiamente tal.

El segundo punto de fuga a esta posible crítica de monologismo en las novelas se encuentra ubicado entre el susurro de la lengua al que aludíamos y la anterior característica recientemente referida, en tanto que completa el sentido de ambas. Nos referimos al discurso de los narradores de ambas novelas, discurso que, amparándonos en Candido, puede definirse por su trabajo con la elipsis y los sintagmas mínimos, es decir, instala blancos discursivos, silencios dentro de la obra. En el caso de la primera y referido a Aliste, el sepulturero, en donde la vida y las características de este personaje ocupan tan solo un par de líneas:

No sembraba, no pescaba, no hacía casas. Ni siquiera tenía hijos. Su oficio era enterrar a los que voluntaria o inadvertidamente morían. Era poco querido, porque su presencia evocaba recuerdos tristes y sugería certidumbres atroces. (p. 101)

Y el siguiente ejemplo de Vidas sêcas en donde la descripción tanto del entorno y como del interior de Fabiano, en el momento en que se le viene a la cabeza el recuerdo de Baleia, recientemente asesinada por él, está expresado en pocas líneas:

\footnotetext{
Tirou do bolso o rolo de fumo, preparou um cigarro com a faca de ponta. Se ao menos pudesse recordar-se de fatos agradaveis, a vida nao seria inteiramente ma. Deixara a rua. Levantou a cabeca, viu uma estrela, depois muitas estrelas. As figuras dos inimigos esmoreceram. Pensou na mulher, nos filhos e na cachorra morta. Pobre de Baleia. Era como se ele tivesse matado uma pessoa da familia. ( $p$. 98)
}

Macherey (1974), postula la tesis de que todo texto artístico se sostiene más en lo que no dice que en lo que efectivamente dice:

Lo que dice el libro viene de cierto silencio; su aparición implica la "presencia" de un no dicho, materia a la que da forma, o fondo sobre el cual toma figura. De este modo, el libro no se basta a sí mismo: necesariamente la acompaña una cierta ausencia, sin la cual no sería. Conocer el libro implica que esta ausencia también sea tenida en cuenta" (MACHEREY, 1974, p. 86) 
De esta forma, lo que es dicho exige un no dicho que lo circunde, ya que para lograr decir algo "hay otras que es necesario no decir" (MACHEREY, 1974, p. 86). Lo que equivale a que todo decir, para llegar finalmente a constituirse como tal, se envuelve en el pliegue de un no dicho. Para de esta manera llegar a establecer que.

\begin{abstract}
una palabra se convierte en obra a partir del momento en que suscita tal ausencia. Lo que hay de esencial en toda palabra es su silencio: lo que ella llega a callar. El silencio da su forma a lo visible. (MACHEREY, 1974, p. 86, la cursiva es nuestra)
\end{abstract}

Lo que no nos parece alejado de Steiner (1997) de que cuando no hay nada que decir es porque son otros lenguajes lo que tienen la palabra: mirar, escuchar, sentir, a los que podríamos agregar los sonidos guturales y monosilábicos de los personajes de Alhué y Vidas sêcas y las dosis de silencio de sus narradores. Esto, según el mismo Steiner, porque lenguaje y silencio se requieren, ya que el silencio no es falta o privación de lenguaje sino, antes bien es en el lugar en el cual reside el silencio donde puede elevarse, estallar la voz unívoca de los cuerpos. Sin embargo, en este último punto no coincidimos con Steiner, ya que más bien en nuestro caso ocurre lo contrario: es en el silencio donde estallan las múltiples voces de los sujetos fragmentarios. Planteado de esta manera el asunto, si lo que revelaba la política del susurro de la lengua efectuada por los personajes de Alhué y Vidas Sêcas eran las limitaciones del lenguaje verbal articulado y el uso de este llevado a cabo por un "poder panóptico", la política del silencio adoptada por los narradores de tales relatos vienen a completar este sentido de manera artística, ya que debido a esas mismas limitaciones, en términos de cosa-signo, en el plano artístico esta misma situación conduce a que "la palabra termina por decirnos más nada: es al silencio al que se interroga, puesto que es el que habla" (MACHEREY, 1974, p. 87), completando de esta manera la estilización de los fenómenos de balbuceo lingüístico y monosilabismo presente en las novelas, puesto que:

\footnotetext{
Lo que es importante en una obra es lo que no dice. No es lo que se nota rápidamente, es lo que ella se niega a decir; [...] O más bien, lo que es importante es lo que ella no puede decir, porque allí se efectúa la elaboración de una palabra, en una especie de marcha al silencio. (MACHEREY, 1974, p. 87-8).
}

Este hecho también nos sirve para explicar, por una parte, el humor presente en los relatos, en tanto que el humor también se funda en lo que se omite, y que podríamos apreciar en Alhué en que, por ejemplo: "Tan pronto como la oscuridad deshacía la calle, desaparecían los raros transeúntes. Y hacían bien. A esa hora las parejas que no querían llegar al matrimonio en estado de perfecta inocencia, buscaban el amparo del bosque." (p. 81). Y en Vidas sêcas, con un tono más político: "Tenha paciencia. Apanhar do governo nao e desfeita." (p. 33). 


\title{
5. Un apunte final
}

Advertimos que el gesto de la moral del lenguaje en los personajes de Alhué y Vidas sêcas y el gesto del silencio artístico de sus narradores se unen en el límite del lenguaje apuntalado por la relación cosa-signo, para reivindicar a través de una opción crítica, la condición del lenguaje que es, en último término, la condición humana; ya que como arguye Steiner (1972) la característica especialmente diferencial del hombre es que es un zoon phonanta, un animal que habla. Planteado el asunto de esta manera, y tomando en consideración lo esbozado por Sollers, esto es que "decir alguna cosa es situarla en el espacio donde esta cosa y el decir que se considera que apunta coexisten sin anularse" (SOLLERS, 1978, p. 117), la aldea que es Alhué y el sertón brasileño serían ese espacio; en la medida en que es en ambos espacios donde la práctica espacial productiva termina deshumanizando a quienes habitan allí, situándolos al margen del proceso modernizador, pero ellos finalmente terminan diciendo, o lo que es lo mismo decir, terminan resistiendo, optimizando de manera artística los recursos que les son propios y que aparentemente se presentan como falencias. En un último plano, estas políticas se con-dicen con las particularidades geoculturales del territorio, ya que como plantea Kusch, en la persistencia del puro "estar" americano, enfrentado al "ser" europeo (enfrentamiento visto en el subcapítulo anterior) hay un uso del silencio: "No se trata del silencio de no decir palabras, sino del silencio que hay aún cuando se habla: el silencio que consiste en no decir cosas esenciales" (KUSCH, 1962, p. 203). Un silencio que Kusch atribuye al ayuno ante la constante "fiesta del mundo". "El ayuno es la abstracción del mundo, a fin de que cada uno busque su fuerza dentro de sí mismo" (KUSCH, 1962, p. 205). Si por nuestras características como latinoamericanos no hiciésemos esto:

\begin{abstract}
Terminaríamos en el despilfarro o, lo que es lo mismo, en la guerra por los objetos o en el lanzamiento de cohetes interplanetarios para alcanzar la luna. Pero sabemos que no haremos ese viaje. Al fin y al cabo somos pobres, y pertenecemos a esa porción que debe quedarse aquí luchando con las tormentas y la ira divina [...] Cuando en occidente el liberalismo plantea la franca disputa de alimentos, lo hace al cabo de haber llegado biológicamente a un pensamiento causal que habrá de canalizar la economía moderna. Entonces, convertir el alimento en mercancía no era grave para esa cultura, pero es imperdonable en América, sencillamente por el margen de sacralización en que aún se debate el problema, no sólo en el mundo indígena, sino también en los suburbios de la gran ciudad americana. (KUSCH, 1962 , p. 207 y 230-1, la cursiva es nuestra).
\end{abstract}

Los retirantes en busca de agua y alimento en Vidas sêcas y el narrador de Alhué que se desplaza con su familia para encontrar un lugar donde subsistir representan esta posición de ayuno, significado como un límite fronterizo entre la escritura (símbolo de occidente) y la oralidad (símbolo de nuestro continente en los albores de su arrastre hacia la occidentalización), en términos de una moral humana presentada a partir de una moral del lenguaje, propia de la geocultura latinoamericana, levantando una posición de resistencia, y esto es lo importante, que 
nace a partir de una comunión con la tierra que les es propia y que cumple la función de relacionar su experiencia inmediata, su vivencia de lo local, con la construcción de una conciencia que signifique las anomalías de un proceso histórico que no ha hecho sino agudizar las drásticas diferencias al interior de las naciones, lo que ha traído como consecuencias, agudos problemas de comunicación, tan agudos como los representados por Alhué y Vidas sêcas.

\section{Referências}

BAJTÍN, M. Estética de la creación verbal. Buenos Aires: Siglo veintiuno editores, 2002

BARTHES, R. El susurro del lenguaje. Barcelona: Paidós, 1987

El grado cero de la escritura. Buenos Aires: Jorge Álvarez, 1967

CANDIDO, A. Formaçao da literatura brasileira: momentos decisivos. Río de Janeiro: Academia brasileira de letras, 2006

Crítica radical. Caracas: Ayacucho, 1991

. Introducción a la literatura de Brasil. Caracas: Monte Ávila, 1968

CORNEJO POLAR, A. Escribir en el aire: ensayo sobre la heterogeneidad sociocultural en las literaturas andinas. Lima: Latinoamérica editores, 2003

. "Condición migrante e intertextualidad multicultural: el caso de Arguedas".

Revista de crítica literaria latinoamericana 42: 101-109, 1995

GENETTE, G. Figuras: retórica y estructuralismo. Córdoba: Nagelkop, 1970

GONZÁLEZ VERA, J. S. Alhué. Santiago. Nacimiento, 1976

KUSCH, R. América profunda. Buenos Aires: Hachette, 1962

MACHEREY, P. Para una teoría de la producción literaria. Caracas: Universidad Central de Venezuela, 1974

RAMOS, G. Vidas sêcas. Río de Janeiro: Record, 1986

SILVA, A. Imaginarios urbanos. Bogotá. Arango editores, 2006

SOLLERS, P. La escritura y la experiencia de los límites. Valencia: Pre-textos, 1976

STEINER, G. Lenguaje y silencio. Ensayos sobre la literatura, el lenguaje y lo inhumano. Barcelona: Gedisa, 1994

TRIGO, A. "Memoria: migrancia: modernidá". En: Mabel Moraña (editora) Nuevas perspectivas desde/sobre América Latina. El desafío de los estudios culturales Santiago: Lom, 2000. 


\section{Title}

For a moral of language on the problematic regionalism: Alhué by José Santos González Vera and Vidas Sêcas by Graciliano Ramos.

\section{Abstract}

This article propose that the position about languaje that the narrator and characters, in the novels Alhué by José Santos González Vera and Vidas sêcas by Garciliano Ramos, starting from the comunión of the rural space, is presented as a critical option agains the problems of the new posibilities of the human condition imposed by de modernity and its production circuits. The reflexión on this "moral of lenguaje" it's framed by the problematic regionalism denominated by Antonio Candido, trying to enclose, from a comparative studie, some of the encounter points between the representative of the chilean criollism and the brasilian serton novel

\section{Keywords}

Problematic regionalism. Moral of language. Alhué. Vidas sêcas.

Recebido em 18/09/2012. Aprovado em 20/10/2012. 